\title{
Lung carcinoma with diffuse cystic lesions misdiagnosed as pulmonary langerhans cell histocytosis: a case report
}

\author{
Xianhua Guil ${ }^{1 \dagger}$, Jingjing Ding ${ }^{1 \dagger}$, Yan $\mathrm{Li}^{1}$, Min Yu${ }^{1}$, Tingting Chen ${ }^{2}$, Mei Huang ${ }^{1}$ and Yonglong Xiao ${ }^{1 *}$ (D)
}

\begin{abstract}
Background: Cystic airspace is an uncommon imaging manifestation involved in non-small lung cancer (NSCLC). Diffuse cystic lesion is even rarer as pulmonary manifestation of NSCLC. In the present study, we reported a rare case of NSCLC associated with progressive diffusion of cystic lesions misdiagnosed as Pulmonary langerhans cell histocytosis (PLCH), finally diagnosed by transbronchial cryobiopsy (TBCB).

Case presentation: A 52-year-old woman was admitted to our hospital due to cough and dyspnea. Highresolution computed tomography (HRCT) presented diffuse cystic shadow mostly, concomitantly with nodular densities in bilateral lungs. A lung biopsy revealed poorly differentiated adenocarcinoma with vascular tumor emboli. The epidermal growth factor receptor (EGFR) mutation on exon 18 (G719X, G719) was detected by mutation test. The patient received treatment of tyrosine kinase inhibitor (afatinib).
\end{abstract}

Conclusions: Diffuse cystic lesion can be a rare manifestation of lung cancer. It was important to improve the recognition of diffuse cystic lung diseases to avoid misdiagnosis.

Keywords: Diffuse cystic lesion, Chest computed tomography, Lung adenocarcinoma

\section{Background}

Diffuse cystic lung diseases (DCLDs) are a group of pathophysiologically heterogenous processes characterized by the formation of multiple thin-walled cystic lesions in the lung parenchyma [1]. DCLDs are rarely caused by a malignant process, which are secondary to metastases from adenocarcinomas of the gastrointestinal tract $[2,3]$ and sarcomas of various cell types $[4,5]$. In the present study, we described the clinical characteristics of a DCLD patient associated with lung cancer diagnosed by transbronchial cryobiopsy (TBCB) in our hospital. Our findings provided valuable insights into the early identification of this type of lung cancer.

\section{Case presentation}

A 52-year-old woman was referred to our hospital with a 1-year history of progressive breathlessness and

\footnotetext{
* Correspondence: yonglong11a@163.com

${ }^{+}$Xianhua Gui and Jingjing Ding contributed equally to this work.

${ }^{1}$ Department of Respiratory and Critical Care Medicine, The Affiliated Drum

Tower Hospital of Nanjing University Medical School, No. 321 Zhongshan

Road, Nanjing 210008, Jiangsu, People's Republic of China

Full list of author information is available at the end of the article
}

productive cough with white sputum. The patient had no occupational exposure and had a ten-year smoking history. Computed tomography (CT) showed multiple cysts and nodules (Fig. $1 \mathrm{a}$ and b). Pulmonary langerhans cell histocytosis (PLCH) was considered basing on the imaging manifestation and smoking history without evidence of histopathology due to limited medical care, and treated with giving up smoking. After 6 months, repeated chest CT scan revealed rapid progress, exhibiting disseminated thin-walled cystic lesions in bilateral lungs (Fig. $1 \mathrm{c}$ and d). Finally, the patient was transferred to our hospital with progressive breathlessness and aggravated cough.

Physical examination on admission included body temperature $36.3^{\circ} \mathrm{C}$, the blood pressure $115 / 74 \mathrm{mmHg}$, respiratory frequence 19 times per minute, heart rate 80 times per minute and auscultation of her lung revealed decreased breath sounds. The oxygen saturation (SpO2) was $93 \%$ in ambient air.

Significant laboratory values were as follows: normal autoimmune markers, normal anti-neutrophil cytoplasmic antibody level, no evidence of infection in sputum

(c) The Author(s). 2020 Open Access This article is distributed under the terms of the Creative Commons Attribution 4.0 International License (http://creativecommons.org/licenses/by/4.0/), which permits unrestricted use, distribution, and 


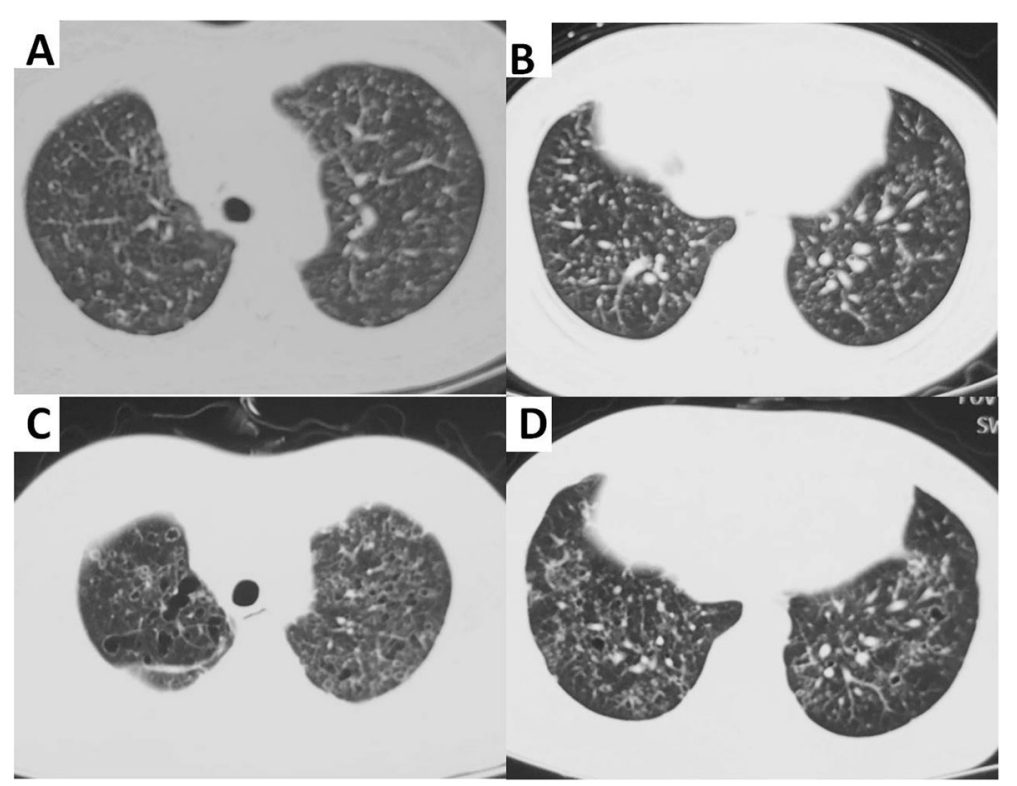

Fig. 1 Computed tomography (CT) scan of the thorax. $\mathbf{a}, \mathbf{b}$ CT of the thorax on February 2018 showed diffuse nodules and cysts distributing in bilateral lung. c, d Repeated Chest CT on August 2018 revealed enlarged, widespread, disseminated thin-walled cysts with different shape

culture, an increased serum white cell count of $11.6 \times$ $10^{9} / \mathrm{L}\left(4-10 \times 10^{9} / \mathrm{L}\right)$. A severely mixed ventilatory defect was detected by pulmonary function test, showing a forced vital capacity (FVC) of $1.37 \mathrm{~L}$ ( $47.6 \%$ of predicted value), a forced expiratory volume in $1 \mathrm{~s}$ (FEV1) of 1.00 $\mathrm{L}(42.6 \%$ of predicted value) and severe reduction of diffusion capacity (DLCO) of 1.94 L (27.4\% of predicted value). Echocardiogram showed mild-to-moderate pulmonary hypertension $(48 \mathrm{mmHg})$.

Repeated HRCT revealed obvious deterioration with diffuse pulmonary cystic lesions, pericardial effusion and bilateral pleural effusion (Fig. 2 a and b). Bronchoalveolar lavage fluid cytology indicated 5\% neutrophils, 5\% lymphocytes, 55\% histocytes, $10 \%$ ciliated cells and 5\% cancer cells. TBCB showed poorly differentiated adenocarcinoma and vascular tumor emboli (Fig. $2 \mathrm{c}$ and $\mathrm{d}$ ). Immunohistochemical analysis revealed the lung primary site [cytokeratin (CK) 7 and thyroid transcription factor 1 (TTF1) positive]. Abnormal carcino-embryonic antigen (CEA) level of $50.93 \mathrm{ng} / \mathrm{mL}(0-10 \mathrm{ng} / \mathrm{mL})$ and an increased neuronspecific enolase (NSE) level of $4.26 \mathrm{ng} / \mathrm{mL}(0-3.3 \mathrm{ng} / \mathrm{mL})$ were observed. Magnetic resonance imaging (MRI) of the brain suggested possible metastatic tumor in the left frontal lobe. Bone scintigraphic imaging showed multiple bone metastases. Therefore, her clinical stage was T4N0M1c stage IV, and epidermal growth factor receptor (EGFR) mutation test was positive with exon 18 (G719X, G719). She underwent afatinib therapy. The next followup after 1 month demonstrated significant improvement, and the patient was alive (Fig. 2 e and f).

\section{Discussion and conclusions}

DCLD is a set of independent lung diseases, including pulmonary metastases, pulmonary langerhans cell histocytosis (PLCH), lymphangioleiomyomatosis (LAM), BirtHogg Dube (BHD) syndrome and so on $[1,6]$. To date, studies on solitary cystic lung cancer have reported that 3.7\% lung cancer cases are associated with cystic airspaces [7]. However, diffuse cysts are even rarer as pulmonary appearance of non-small lung cancer (NSCLC). To date, DCLDs reported in literature are case reports with adenocarcinoma as the pathologic types of diffuse cystic lung cancer $[8,9]$. It has a unique imaging manifestation different from common lung cancer, which may be a potential cause of misdiagnosis.

The clinical presentation of NSCLC with diffuse cystic lesions is remarkably different from common lung cancer. The patients primarily present with a cough and dyspnea secondary to diffuse infiltration of tumor cells $[8,9]$. In our patient, this was reflected by a mixed ventilatory defect with seriously reduced diffusion capacity of carbon monoxide in pulmonary function test. Affected patients are more likely to develop to respiratory failure.

The radiographic definition of diffuse cystic lesion of the lung is characterized by a thin-walled $(<2 \mathrm{~mm})$, airfilled, spherical lucency in the lung parenchyma. The mechanism underlying the formation of parenchymal cysts in NSCLC remains uncertain. Some scholars have speculated that accumulation of tumor cells in terminal and respiratory bronchioles forms a one-way valve, resulting in excessive peripheral ventilation $[6,10,11]$. It has also been proposed that ischemic necrosis of 


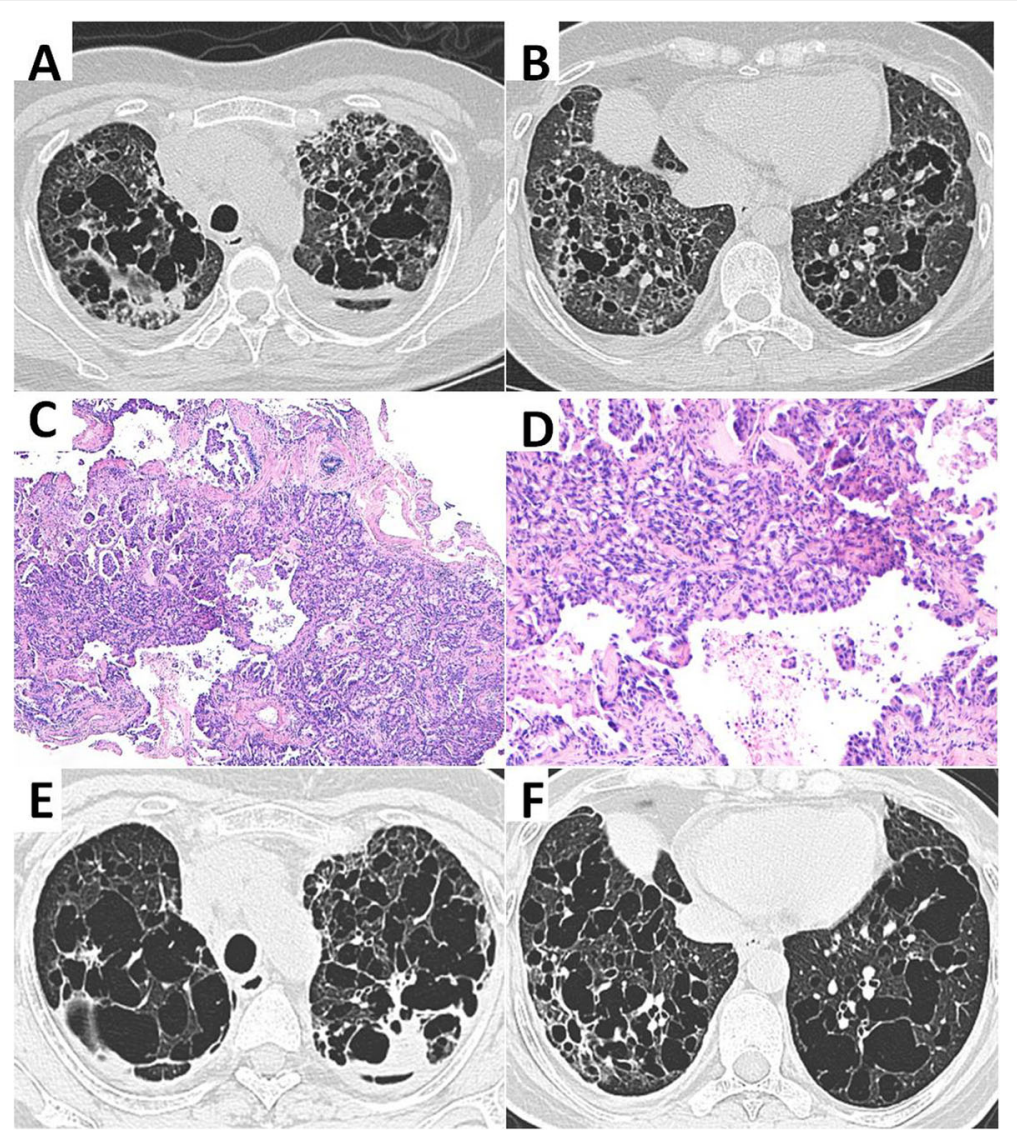

Fig. 2 Chest CT on 2019 and microscopic examination of specimens. a, b Chest CT on March 2019 showed rapid progress, disseminated thinwalled cystic lesions and nodules in bilateral lungs. $\mathbf{c}, \mathbf{d}$ The pathology revealed poorly differentiated adenocarcinoma and vascular tumor emboli. e, f Pulmonary nodules diminished, and the cysts fused bizarrely shaped cysts after 1 month of afatinib therapy

terminal bronchioles and alveoli is induced by infiltration of small vessels and capillaries, leading to alveolar ischemic dilation to form cysts [12]. Our results also suggested an alveolar ischemic dilation mechanism, where the tumor cells infiltrated in vascular system, resulting in alveolar ischemic dilation.

There are a broad set of diseases based on the special imaging manifestation. Accompanying features with invaluable clues can help us distinguish different types of DCLDs, including commonly observed PLCH and LAM. PLCH usually occurs in smokers at $20 \sim 40$ years old, who had a long history of smoking or exposure to second-hand smoke [13]. Centrilobular nodules and bizarrely shaped cysts can appear mainly in upper and middle lung lobe on chest HRCT. Early histopathology reveals bronchiolocentric nodules (accumulation of langerhans cells, eosinophils, lymphocytes and fibroblasts). In later stages, cysts can form because of enlarged airspace and cavitary nodules. Pulmonary langerhans cells positively expressing CD1a and S-100 can help to diagnose such disease [14]. NSCLC associated with diffuse cystic lesions have the similar imaging manifestation to
PLCH, including nodules and cysts, making it difficult to distinguish. As a rare cystic disease, LAM is usually characterized by pulmonary infiltration of smooth muscle cells harboring tuberous sclerosis genes with growth-activating mutations, and such situation often occurs in women of childbearing age $[15,16]$. The chest HRCT presents diffuse distribution of uniform-sized thin-walled cysts, which is often accompanied with renal angiomyolipomas on abdominal CT [17]. Thus, similar imaging manifestations make it difficult to distinguish LAM from other cystic lung disease. The final diagnoses depend on the pathology of lung tissue.

Collectively, diffuse thin-walled cysts in chest-CT are rare imaging manifestations of lung cancer, which is often ignored and misdiagnosed as other cystic lung diseases due to similar imaging findings. Early recognition of this infrequent radiologic feature of lung cancer and prompt therapy are important.

\section{Abbreviations}

CEA: Carcino-embryonic antigen; DCLDs: Diffuse cystic lung diseases; DLCO: Diffusion capacity; FEV1: Forced expiratory volume in $1 \mathrm{~s}$; FVC: Forced vital capacity; HRCT: High-resolution computed tomography; 
LAM: Lymphangioleiomyomatosis; MRI: Magnetic resonance imaging; NSCLC: Non-small lung cancer; NSE: Neuron-specific enolase;

PLCH: Pulmonary langerhans cell histocytosis; $\mathrm{SpO}_{2}$ : Oxygen saturation; TBCB: Transbronchial cryobiopsy

\section{Acknowledgements}

No applicable.

\section{Authors' contributions}

XHG and JJD made the diagnosis and wrote the manuscript and all authors carefully revised the manuscript. TTC made the pathology section and immunohistochemical stain. YL and MH cared for and followed up the patient. MY did the TBCB. YLX assisted with revising the manuscript. All authors have read and approved the final version of this manuscript.

\section{Funding}

The authors declare no funding was received for this study.

\section{Availability of data and materials}

The datasets used and/or analyzed during the current study available from the corresponding author on reasonable request.

\section{Ethics approval and consent to participate}

The Ethics Committee of Drum Tower Hospital of Nanjing university approved this study. The patient agreed to participate in this study with all relevant data. And written informed consent was obtained from the patient.

\section{Consent for publication}

Written informed consent was obtained from the patient for publication of the case report.

\section{Competing interests}

The authors declare that they have no competing interests.

\section{Author details}

${ }^{1}$ Department of Respiratory and Critical Care Medicine, The Affiliated Drum Tower Hospital of Nanjing University Medical School, No. 321 Zhongshan Road, Nanjing 210008, Jiangsu, People's Republic of China. ${ }^{2}$ Department of Pathology, The Affiliated Drum Tower Hospital of Nanjing University Medical School, No. 321 Zhongshan Road, Nanjing 210008, Jiangsu, People's Republic of China.

Received: 27 August 2019 Accepted: 28 January 2020

Published online: 04 February 2020

\section{References}

1. Gupta N, Vassallo R, Wikenheiser-Brokamp KA, et al. Diffuse cystic lung disease. Part I. Am J Respir Crit Care Med. 2015;191(12):1354-66.

2. Stern E, Huseini T, Kuok Y, et al. Metastatic pancreatic carcinoma masquerading as cystic lung disease: a rare presentation. Respirology case reports. 2017;5(5):e00246.

3. Fielli M, Avila F, Saino A, Seimah D, et al. Diffuse cystic lung disease due to pulmonary metastasis of colorectal carcinoma. Respir Med Case Rep. 2016; 17:83-5.

4. Hasegawa S, Inui K, Kamakari K, et al. Pulmonary cysts as the sole metastatic manifestation of soft tissue sarcoma: case report and consideration of the pathogenesis. Chest. 1999:116(1):263-5.

5. Hoag JB, Sherman M, Fasihuddin Q, et al. A comprehensive review of spontaneous pneumothorax complicating sarcoma. Chest. 2010;138(3):510-8.

6. Gupta N, Vassallo R, Wikenheiser-Brokamp KA, et al. Diffuse cystic lung disease. Part II. Am J Respir Crit Care Med. 2015;192(1):17-29.

7. Mascalchi M, Attina D, Bertelli E, et al. Lung cancer associated with cystic airspaces. J Comput Assist Tomogr. 2015;39(1):102-8.

8. Zhang J, Zhao YL, Ye MX, et al. Rapidly progressive diffuse cystic lesions as a radiological hallmark of lung adenocarcinoma. J Thorac Oncol. 2012;7(2): 457-8.

9. Kushima H, Ishii H, Yokoyama A, et al. Lung adenocarcinoma presenting with diffuse multiloculated cystic lesions. Internal Med (Tokyo, Japan). 2013; 52(20):2375
10. Xue X, Wang P, Xue Q, Wang N, et al. Comparative study of solitary thinwalled cavity lung cancer with computed tomography and pathological findings. Lung Cancer (Amsterdam, Netherlands). 2012;78(1):45-50.

11. Isobe $K$, Hata $Y$, Iwata $M$, et al. An autopsied case of mucinous bronchioloalveolar carcinoma associated with multiple thin-walled cavities Nihon Kokyuki Gakkai zasshi = the journal of the Japanese Respiratory Society. 2009;47(6):512-7.

12. Ohdama S, Akagawa S, Matsubara $\mathrm{O}$, et al. Primary diffuse alveolar septal amyloidosis with multiple cysts and calcification. Eur Respir J. 1996;9(7): 1569-71.

13. Vassallo R, Ryu JH, Schroeder DR, et al. Clinical outcomes of pulmonary Langerhans'-cell histiocytosis in adults. N Engl J Med. 2002;346(7):484-90.

14. Schonfeld N, Dirks K, Costabel U, et al. A prospective clinical multicentre study on adult pulmonary Langerhans' cell histiocytosis. Sarcoidosis Vasc Diffuse Lung Dis. 2012;29(2):132-8.

15. McCormack FX, Travis WD, Colby TV, et al. Lymphangioleiomyomatosis: calling it what it is: a low-grade, destructive, metastasizing neoplasm. Am J Respir Crit Care Med. 2012;186(12):1210-2.

16. Henske EP, McCormack FX. Lymphangioleiomyomatosis-a wolf in sheep's clothing. J Clin Invest. 2012;122(11):3807-16.

17. Ciftci AO, Sanlialp I, Tanyel FC, et al. The association of pulmonary lymphangioleiomyomatosis with renal and hepatic angiomyolipomas in a prepubertal girl: a previously unreported entity. Respiration. 2007;74(3):335-7.

\section{Publisher's Note}

Springer Nature remains neutral with regard to jurisdictional claims in published maps and institutional affiliations.
Ready to submit your research? Choose BMC and benefit from:

- fast, convenient online submission

- thorough peer review by experienced researchers in your field

- rapid publication on acceptance

- support for research data, including large and complex data types

- gold Open Access which fosters wider collaboration and increased citations

- maximum visibility for your research: over $100 \mathrm{M}$ website views per year

At BMC, research is always in progress.

Learn more biomedcentral.com/submissions 